\title{
Suspiciously Convenient Belief
}

\section{Neil Levy ${ }^{1,2}$}

Accepted: 7 August 2020 / Published online: 20 August 2020

(C) The Author(s) 2020

\begin{abstract}
Moral judgments entail or consist in claims that certain ways of behaving are called for. These actions have expectable consequences. I will argue that these consequences are suspiciously benign: on controversial issues, each side assesses these consequences, measured in dispute-independent goods, as significantly better than the consequences of behaving in the ways their opponents recommend. This remains the case even when we have not formed our moral judgment by assessing consequences. I will suggest that the evidence indicates that our perception of the consequences of acting as recommended by our moral judgments is motivated, such that the warrant of such assessments is lower than we might have thought. The suspicion correlation between our moral judgments and our assessments of the implicated facts provides higher-order evidence that should lead us to reduce our confidence in these assessments.
\end{abstract}

Keywords Moral judgment $\cdot$ Coincidence $\cdot$ Higher-order evidence $\cdot$ Conciliationism

There is no moral precept that does not have something inconvenient about it.

Denis Diderot.

We - most of us at any rate - appear to take ourselves to live in a morally benign world. Whatever our moral beliefs we seem to think that the world cooperates with our moral endeavours. In this paper, I will argue that this optimism manifests itself in ways that are epistemically suspicious: we take the facts to fit with our moral judgments suspiciously well, even when we have not taken those facts into account in forming our moral judgments. I will argue that recognition of this suspicious fit between our moral judgments and our perception of the facts - especially facts about the consequences of acting consistently with our moral judgments - gives us reason to reduce our confidence in our assessment of these facts.

Neil Levy

neil.levy@philosophy.ox.ac.uk

1 Department of Philosophy, Macquarie University, Sydney, NSW 2109, Australia

2 Uehiro Centre for Practical Ethics, University of Oxford, Oxford OX1 1PT, UK 
Let me flesh this out a little. Moral judgments consist in, entail or commit us to thinking that certain ways of behaving or refraining are permissible or required. These acts and omissions can be expected to have certain effects on the world (I will assume for simplicity that talk about the causal powers of omissions can be cashed out in terms of counterfactuals). To an extent that is (I will argue) surprising, people judge that these effects will be benign. Doing the right thing carries few costs. Slightly more carefully, when we form a moral judgment about a controversial issue, we usually judge that what I will call the implicated facts - facts about the effects of conforming to that judgment (typically the effects of people in general conforming to the judgment: the aggregated effects of us adopting a policy of acting like that) - will be benign compared to the effects of conforming to alternative moral judgments, where these effects are measured in dispute-independent goods (or a reduction in harms measured in such goods). A good is dispute-independent when both or all contending sides agree that (and how) it matters. Goods like welfare, health, solidarity are thus (typically, at very least) disputeindependent, even if different people place different weights on them (conversely, putative goods like rights protection, or sanctity are often not dispute-independent, because some disputants reject the claim that they exist, or that they are valuable). A good may be dispute-independent relative to one dispute but not another: one dispute may pit two groups who both value (say) respect for hierarchy, while another pits two groups who have conflicting attitudes about that same (putative) good.

I will argue that the correlations between our moral judgments and our beliefs about the effects of acting consistently with these judgments are suspicious. Moreover, I will argue that the most plausible explanation for the correlation is that our moral judgments bias our beliefs about the implicated facts. For instance, judging that use of recreational drugs is wrong implicates facts about the kind of society in which drug use is tolerated or allowed to take place, about the character of those who engage in it, about the unfolding of the lives of drug users, and so on. I will argue that beliefs about these implicated facts are suspiciously correlated - those who judge recreational drug use wrong have significantly more negative views about these facts than those who judge it permissible, for instance - and that an important part of the explanation for this correlation is that the moral judgments bias our assessment of these facts. I will suggest that recognition that we are prone to such correlations puts pressure on us to reduce confidence in these beliefs. Many philosophers argue that in the face of disagreement with an epistemic peer, we ought to conciliate; that is, adjust our credence in the disputed belief in the direction of our peer's credence (see Christensen and Lackey 2013; Matheson 2015 for discussion). I will argue that the suspicious correlation puts us under additional pressure to reduce our confidence in some, but not all, of our controversial beliefs. I will call such a reduction in confidence conciliation, whether or not there is a dissenting peer with whom to conciliate.

It should be noted at the very outset that I am neither the first to notice the suspicious correlation nor to suggest that it provides a reason to reduce our confidence in our beliefs concerning implicated facts. In a recent paper, Daniel Greco (n.d.) does both these things. ${ }^{1}$ Greco's aim in that paper is to assess the epistemic standing of one particular class of beliefs: our assessment of the reliability of apparent experts. He ties his account closely to a particular psychological theory (Dan Kahan's cultural cognition hypothesis), though he recognizes that the problem he points to is broader. I will show that the problem is in one way more general

\footnotetext{
${ }^{1}$ Franklin too (2009: 282) notes "a suspiciously high correlation between the belief that torture is ethical and the belief that torture is effective."
} 
than Greco recognizes and in another narrower. It is more general in that it affects a very broad range of belief pairs. It is narrower, and therefore more pointedly focused, in that it casts suspicion on one member of each pair, not both. I will also show that the problem arises independently of any specific psychological theory. The correlations are suspicious, however they arise, and they give us good reason to conciliate. I aim to demonstrate that the problem extends well beyond our assessments of expertise, and to consider a range of objections that Greco leaves untouched. ${ }^{2}$

I will proceed as follows. I section one, I will provide evidence for the existence of a high degree of correlation between people's moral judgments and their beliefs about the facts implicated by these judgments. In section two, I will argue that the correlation appears to arise in important part from a biasing of our beliefs about these facts by our moral judgments, and that therefore suspicion falls on these beliefs, and not on our moral judgments. In the third section, I will examine possible strategies for resisting the pressure to conciliate that arises from the suspicious correlation, and assess the extent to which the argument from suspicious correlation is reducible to the familiar argument from peer disagreement. I conclude that the arguments are distinct, and that the suspicious correlation gives us an additional reason for humility with regard to our beliefs concerning the facts implicated by our moral judgments.

\section{Fishy Facts}

My first task is to establish that our moral judgments and our beliefs about the implicated facts (in particular, facts about the effects of acting consistently with our moral judgments) correlate to an extent that is surprising. I leave till later sections the issue whether the correlation is in fact fishy, or can instead be explained in a way that renders it epistemically benign.

Let's begin with some data, before turning to the correlation as it manifests within philosophy itself. In all domains for which we have evidence (as far as I have been able to ascertain), people appear to believe that the implicated facts support their moral judgments, even when they don't seem to have formed their moral judgments on the basis of a prior assessment of the facts. Lord et al. (1979) is a famous early study providing some preliminary evidence for the correlation. They gave participants mixed evidence concerning the deterrent effect of capital punishment. Proponents and opponents of the death penalty failed to moderate their attitudes in the face of this mixed evidence. Rather, they evaluated evidence supportive of their own prior views more favourably than evidence that opposed it, and their attitudes hardened. Thus, they apparently expected the world to be compliant with their prior moral judgment, rather than forming their moral judgment on the basis (in part) of their evaluation of independent facts.

Later work on the same topic provides similar, but stronger, evidence. Opponents of the death penalty may cite moral grounds for their views, but they expect the world to cooperate: it is the rare opponent who claims that they oppose the death penalty despite the fact that it deters crime (Lambert et al. 2004; Stack 2004). Opponents of the death penalty believe that it is ineffective as a deterrent and the risk of executing an innocent person is high; those who support it have the opposite empirical beliefs. At least insofar (as is typical) as views about the

\footnotetext{
${ }^{2}$ The suspicious correlation is also closely related to the problem of partisan polarization noted by Joshi (2020); the epistemically suspicious pattern of anticorrelation of our beliefs with those of our political opponents. The suspicious correlation does not require partisan clustering to arise or even actual disagreement.
} 
death penalty are not founded on consequentialist considerations, the correlation seems suspicious (later, I will argue that consequentialists, too, may exhibit the suspicious correlation). It is a striking coincidence that the world (as they see it) comports so well with everyone's views.

The phenomenon extends well beyond the issue of capital punishment (See Seipel 2019 for further examples). Kahan et al. 2007 cite evidence that opponents of gun control have different factual beliefs about the risks of guns to proponents, with the former thinking that restrictions increase the risks of crime and the latter holding that restrictions reduce it. Indeed, they turn out to differ not only in first-order beliefs about the facts,but also in their beliefs about what relevant experts believe about the facts (Kahan et al. 2010). The world is so obliging that the genuine experts can be relied on to have factual beliefs that fit with my moral beliefs (it is this suspicious correlation between people's moral judgments and their assessments of who has genuine expertise that is Greco's focus). This phenomenon, of believing that the experts have factual beliefs that support my policy views, occurs with regard to climate change too. Perceptions of the expert consensus on climate change have been described as the gateway to scepticism (van der Linden et al. 2015, 2019).

Let's turn now to examples within philosophy itself. Consider, to take a more or less random example, debates in ethics over human enhancement. Opponents of enhancement typically base their opposition on non-consequentialist considerations, such as the protection of human dignity (e.g., Habermas 2003). But they hold that the use of enhancements would nevertheless have a variety of undesirable consequences: the perception of children as commodities (Sandel 2009), an increase in inequality (Fukuyama 2002; Hauskeller 2013), placing those who prefer to remain unenhanced under unreasonable pressure (Chatterjee 2004) and an increase in stigma and discrimination against the disabled (Wolbring 2009). Enhancements would also be bad for general health (Cakic 2009), and would not achieve their goals, in any case, since in a world in which everyone is enhanced no one has any advantage (Birch 2005). In stark contrast, supports of enhancement argue that the consequences would be positive: inequality would shrink, rather than increase (Veit 2018) and enhancement would have a number of positive externalities (Sandberg and Savulescu 2014).

I'm certainly not claiming that everyone exhibits the pattern seen here. I am suggesting, however that it is widespread and that the effect is strong. I suspect most philosophers exhibit this pattern on most issues, and that the same is true - perhaps to an even greater extent among the general public. For instance, liberals and conservatives (a) diverge on moral issues like the permissibility of enhancement; (b) tend to diverge in their perception of the consequences of the policies and issues on which they disagree; and (c) this remains true even when their moral judgments are not based on the consequences perceived. As Clarke (2017) notes, for instance, conservatives and liberals differ not only on what should be done, but also on facts about possible interventions, with conservatives judging that interventions are significantly more risky than do liberals (see also Seipel 2019).

The risk of cherry picking, or of confirmation bias, is surely high here. Perhaps the correlation between moral judgments and perceptions of non-moral facts is lower than I think. In concluding this section, though, I'd like to call attention to some features of very familiar disputes in the political and moral realms. I'm not going to cite any data to back up the claims I make: I hope, rather, that they will resonate with readers. I start with an example from the UK context: Brexit.

'Leavers' typically cite as their main motivation for their view that too many important decisions about the future of the nation are in the hands of the EU, rather than the United 
Kingdom, and (very importantly) that the UK has insufficient say in who immigrates and in what numbers. Despite the fact that these worries about 'sovereignty' were principal motivators of the leave vote, few leavers held that the UK will pay significant economic costs for leaving the union. On the contrary, leavers largely hold that the UK will benefit economically from leaving the EU. 'Remainers', on the other hand, are welcoming of immigration, which they hold to be intrinsically valuable, and also to be beneficial economically. Leavers hold that delaying Brexit will empower the far right; Remainers hold that Brexit itself will empower the far right.

In the US context, we see similar patterns. Trump supporters believe that his economic and social policies will decrease unemployment (by lowering taxes on business, enabling them to employ more staff and by decreasing legal and illegal immigration), while opponents tend to think that these same policies will lead to recession (driven by lower consumer and governmental spending) which will drive up unemployment. Yet in very many cases, support and opposition are not primarily predicated on economic views. Or take climate change. I believe that a transition to a green economy is not merely required to combat it, but will have economic benefits: nations that lag behind will be at a disadvantage as economies transform. But those who judge that climate change is not a major threat believe that it would be economically disastrous to address it. All these correlations strike me as suspicious, even in my own case, and my anecdotal evidence from discussing the correlation with others seems to suggest that most reflective people recognize it in themselves.

I won't attempt to provide any further evidence for the existence of the correlation. In the next section, I turn to a preliminary explanation of it. My aim is to explain why moral judgments correlate with implicated facts. Do beliefs about the facts cause our moral judgments? Or is the causal arrow in the opposite direction? Or does it run in both directions simultaneously? Identifying the direction of causation matters, I shall argue, because it allows us to identify which particular correlated beliefs are suspicious in the light of the correlation.

\section{The Direction of Causation}

Everyone, consequentialist or not, takes consequences into account in forming their moral judgments. This fact provide a neat explanation for the correlation; an explanation, moreover, that renders it justified. We want our moral judgments to be causally sensitive to the implicated facts. In this section, however, I will suggest that the fit between our moral judgments and the world is not the product of such sensitivity to an extent sufficient to render the correlation unsuspicious. The direction of causation is at least partly from moral judgment to implicated facts. We even expect these facts to change to suit us, if we happen to change our minds.

Even those agents who are not card-carrying consequentialists (I set card-carrying consequentialists aside until the next section) can and do exhibit sensitivity to the implicated facts in forming their moral judgments. Non-consequentialists accept that welfare, happiness, and so on are genuine goods, even if they don't accept that they ground (or always ground) moral judgments. In many circumstances, the balance of these goods settles how we should act. Further, even moral judgments grounded in rights or virtues may be influenced by implicated facts. For example, agents who think that certain ways of acting have detrimental consequences might be motivated to examine arguments for acting in those ways more critically than they otherwise would. This would help to explain a rough correlation between perceptions of the consequences and moral judgment, mediated by attention. 
While these facts surely help explain the correlation between moral judgments and assessments of implicated facts, there is evidence that the causal arrow also runs in the opposite direction: from moral judgment to non-moral perception. Liu and Ditto (2013) had participants read pro or anti-death penalty arguments. The arguments were effective in changing attitudes toward the death penalty. More interestingly, though, they also brought about significant differences in participants' perceptions of the implicated facts, even though these facts were not mentioned in the arguments. Thus, those who read arguments opposing the death penalty on deontological grounds assessed the deterrent effect of the penalty as smaller, and the risk of executing the innocent higher, than those who read arguments in favour of its use, while assessment of the implicated facts shifted in the opposite direction for those who read arguments supporting the death penalty on retributivist grounds. The stronger the moral conviction, moreover, the greater the shift in the assessment of the implicated facts.

Further, albeit weaker and less direct, support for the hypothesis that the causal arrow runs from moral judgment to implicated facts comes from a study by Kahan et al. (2015). They had participants read an article outlining the bleak consequences of climate change. Prior to reading the material, they read one of two articles outlining responses to climate change - one advocating for geoengineering, one for strict emissions control - or a control article. Kahan and colleagues found that 'hierarchical individualists,' who place a high value on the free market, were more sympathetic to the claims of the target article after presentation of the geoengineering piece than the emissions control piece, and egalitarian communitarians, who are suspicious of the market, moved in the opposite direction. This provides indirect support for the claim that the causal arrow runs from moral judgment to facts. Participants' readiness to accept factual claims concerning climate change was influenced by the availability of a response that comported with their broader political views.

The mechanism underlying the motivated revision of beliefs about implicated facts is unclear. $^{3}$ Liu and Ditto (2013) suggest that some kind of need for explanatory coherence might explain their data, but acknowledge this is speculative. The experience of cognitive dissonance and well-known biases like the confirmation bias, salience bias and the affect heuristic might all play a role. For our purposes, the precise mechanism need not matter: what matters is that the mechanism, whatever it is, does not appear capable of vindicating the revised belief.

Why does it matter whether it is true, as I claim, that that the causal arrow runs from moral judgments to implicated facts? First, it is important because the reverse direction of causation helps to exonerate correlated beliefs: there is nothing suspicious about taking consequences into account in forming our beliefs. Second, however, it is also important because it allows us to identify which of our correlated beliefs are suspicious. In particular, it will allow us to move beyond Greco: allowing us to see that suspicion falls only on one member of a pair of suspiciously correlated beliefs.

Greco (n.d.) argues that we ought to be suspicious of any pair of beliefs we hold when we believe that they are coincidentally true together, but the best explanation of why we believe both is non-coincidental. $P$ and $q$ are coincidentally true when the best explanation of $p$ is independent of the best explanation of $q$ (see Owens 1992 for a groundbreaking account along similar lines). On the other hand, they are non-coincidentally true when the best explanation of $p$ overlaps considerably with the best explanation of $q$ (being a coincidence comes in degrees, because two explanations may overlap to varying degrees). Thus, for example, that I find

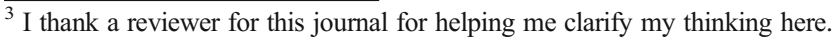


myself sitting next to a fellow philosopher while on a flight is a coincidence if the explanation of her taking that flight is independent of the explanation of my being there (she is going to a workshop which requires her to change planes at our shared destination; I am going to visit my sister). If we are both going to the same meeting, though, the degree to which it is a coincidence is much reduced. My beliefs that $p$ and that $q$ are suspiciously correlated if I believe that $p$ is true for reasons independent of those that make $q$ true, but the explanation for my believing $p$ and $q$ cites some common explanatory factor.

As it stands, Greco's account inappropriately exonerates the suspicious correlation. Agents often maintain there is a good reason why their assessment of the implicated facts correlates with their moral judgments. They may hold that the causal arrow runs from facts to judgment, or they may cite their superior perceptiveness. But the mere fact that the agent believes the correlation holds for some such reason does not rescue it from fishiness. In fact, there are plentiful counterexamples to Greco's first condition. Consider an agent who believes that someone has committed a certain crime and also that people who come from his background are more likely to commit crimes like that. The agent believes that $p$ and $q$ are noncoincidentally true. But he holds these beliefs due to some fact about himself - his prejudices - and not some fact about the world. His beliefs are suspiciously correlated, despite the fact that he takes them to be non-coincidentally true.

The mere fact that an agent cites some common cause for a pair of beliefs does not absolve them of suspicion. Beliefs are suspiciously correlated if they not coincidentally correlated and there is no vindicating explanation of why they should be correlated. They are coincidentally correlated if the correlation lacks predictive power; the fact that instances of $p$ and $q$ have been true together up to $t$ does not provide grounds for thinking that they will be true together after $t$. If it has predictive power, then they are non-coincidentally correlated. There is a vindicating explanation of the correlation if there is a true explanation that explains the belief pair as an appropriate response to evidence: either one member of the pair is an appropriate response to the evidence provided by the other belief (there is nothing suspicious about the correlation between my first-order belief that $p$ and my higher-order belief that I believe that $p$; the first provides evidence for the second) or there are facts about the world that provide evidence in the light of which both members of the pair are formed.

The suspicious correlation seems to have predictive power (tell me your moral views and I have a fair chance of guessing your assessments of implicated facts). It is therefore no coincidence. We render it non-suspicious only if we are able to cite some vindicating explanation of why it holds.

Setting consequentialism aside till the next section, the only explanation that seems to have any chance here, it seems to me, would be one that cited claims about agents' superior capacity to detect moral and non-moral facts. There is currently a lively debate concerning whether bias is more prevalent on one side of politics or the other (Baron and Jost 2018; Ditto et al. 2018); we might appeal to this literature to support of the claim that one side is systematically more reliable than the other. However, there are reasons to be very sceptical of this kind of explanation. If partisan bias is to come to the aid of one side or the other, it must render that side more reliable in both their moral judgments and their assessments of implicated facts. They must have a common cause, in agents' superior capacities. But the evidence cited earlier suggests that assessments of implicated facts are dependent on moral judgments, rather than both having a common cause.

Further, suspicious correlations between moral judgments and assessments of implicated facts do not seem to be restricted to issues on which there is a partisan split (though it may be 
stronger with regard to those issues). Rather, it appears to arise whenever the implicated facts might be sufficiently inconvenient for the person, given her moral judgments. Whenever there is a significant cost to be paid, we are disposed to bow to the pressure and adjust our assessment of the implicated facts.

If a correlation is suspicious, to which judgment in particular (moral judgment? assessment of implicated facts? the conjunction of both?) does suspicion attach? Greco holds that Kahan's cultural cognition hypothesis explains the correlation. On this hypothesis, agents' moral judgments and their perceptions of the non-moral facts are shaped by their cultural identities. Greco argues that on this basis, we should downgrade our confidence in our perception that some experts are more reliable than others: given that we have a certain worldview, that assessment of expertise was predictable. But since cultural identity is supposed by Greco to be the common cause of both the moral judgment and the assessment of expertise, there is no reason to fasten on the latter in particular. We have as good reason to reduce our confidence in our moral judgment, or both conjuncts, as in our assessment of expertise. But the evidence I've cited suggests that Greco's common cause hypothesis does not explain the suspicious correlation (thought it might play a role in explaining our moral judgments; I take no stand on that question). Rather, the correlation arises (at least in significant part) because our moral judgments bias our assessments of the implicated facts, and that - I claim - casts special suspicion on the latter.

While the causal arrow may - likely does - run in both directions, from perceptions of implicated facts to moral judgments and from moral judgments to perceptions of implicated facts, to the extent to which the latter is the case, our moral judgments bias our perception of the implicated facts. To the extent to which this direction of causation plays a role (as I have argued), our perception of implicated facts changes in ways that are insensitive to evidence. It's not because I have gained additional evidence that capital punishment doesn't deter that I increase my confidence that it doesn't (for example). It's because I have become more confident that capital punishment isn't justified for reasons independent of the implicated facts. Since the world does not bend itself to my perceptions, this direction of causation casts doubt on my assessment of the implicated facts and recognition that this is the case provides me with higher-order evidence against that assessment.

If the above claims are correct, each of us has good reason to reduce our confidence in our assessments of the facts implicated by our moral judgments. Our assessments appear to be significantly biased by our moral judgments, such that we live in a suspiciously benign world. Recognition of this fact give us a reason to conciliate on our assessments.

\section{Resisting the Pressure to Conciliate}

The suspicious correlation is indeed suspicious, since there is no vindicating explanation of why it holds. On the contrary, the best explanation cites moral judgments as biasing causes. Given that our moral evaluations seem to be proximate causes of our factual beliefs, the suspicion attaches to these beliefs. These facts seem to constitute higher-order evidence against our factual beliefs, and recognition of these facts give us reason to reduce confidence in our factual beliefs. When we recognize that the best explanation of why we hold a particular belief cites some fact about $u$ s and not the state of affairs that is the intentional object of the belief, we have evidence that the belief is less well-justified than we had hoped. In this section, I explore ways in which we might attempt to resist the pressure to conciliate. 
Consequentialists, who I set aside earlier, seem to be in the clear, as Greco suggests. He compares two libertarians. One bases her libertarianism on considerations about property rights, while the other is a consequentialist. Each of them opposes a certain policy, and in defence of their view each is able to cite what they take to be certain facts (it will stifle competition, lower wages, or whatever). Their moral views and these facts correlate. Greco argues that there is nevertheless an epistemic asymmetry between them. In the first case, this correlation is suspicious: it is a striking coincidence that the facts happen to fall out (again) in a way that supports a position she defends on non-factual grounds. But the correlation between the second libertarian's views and the facts is not coincidental at all. Rather, because her libertarianism is based on her view of the facts, the facts ground the moral view.

On these sorts of grounds, consequentialists may argue that their factual beliefs escape suspicion. To be a consequentialist is to hold a moral theory according to which the facts that are implicated in a judgment determine its correctness, and therefore to be committed as a matter of principle to having moral judgments that correlate with (because they are grounded in) these facts. Since consequentialism predicts the correlation, a consequentialist agent should expect to see the correlation and it does not provide her with higher-order evidence against her perception of the implicated facts.

While it is of course true that consequentialism differs from other normative theories in predicting the correlation, it is far from clear that actual consequentialists are off the hook. Consider, first, Greco's second kind of libertarian, who bases her moral views on her perception of the consequences of libertarian policies. She earns the label 'libertarian', presumably, on the grounds that she typically takes characteristically libertarian stances. She is in the clear, so far as the worry is concerned, only if two conditions hold: (1) when the facts change, such that libertarian stances are not supported by them, she takes other positions and (2) the facts are not suspiciously fixed. No doubt, since she claims to base her libertarianism on consequentialist considerations, our agent will maintain that she satisfies the first condition. But her claim will not be very convincing unless the facts, as she sees them, sometimes lead her to think that a libertarian stance is not appropriate, and some of the occasions on which this is true concern issues that are not entirely trivial. If she never budges, or budges only on issues that are trivial, we rightly find the correlation suspicious.

To put the point in another way: to clear our agent of suspicion, we need evidence that the causal arrow genuinely points from facts to moral judgment, and not the other way round. There is nothing at all suspicious about a match between facts and judgment if there is evidence that facts drive judgment. Good evidence that facts drive judgment will consist in actual, and not merely asserted, sensitivity of judgment to facts. If the person expresses a willingness to abandon her libertarianism whenever the facts dictate that significant, disputeindependent, goods conflict with that stance, but mysteriously never encounters such cases, we have grounds for suspicion. ${ }^{4}$

\footnotetext{
${ }^{4}$ Of course, there' $\mathrm{d}$ be nothing suspicious here if a consequentialism-based libertarianism is the One True moral position. The correlation is just what we would expect if in almost all circumstances in which something significant is at stake, the kind of response that would be advocated by libertarians conduced at least as well as alternatives to bringing about dispute-independent goods (like welfare, preference-satisfaction, efficiency, and so on). Of course, libertarians will believe that this is usually the case. But I don't think it is controversial to suggest that it would be nothing short of miraculous if significant conflicts between libertarian policies and very valuable goods were vanishingly rare. It is a commonplace that the major rival ethical theories overlap very considerably in the policies they support, but equally a commonplace that theory choice matters, because they sometimes conflict in their advice.
} 
We are entitled to be suspicious of non-consequentialists if, mysteriously, they rarely encounter circumstances in which their judgments commit them to paying significant costs, measured in terms of dispute-independent goods. A libertarian who bases her commitments on their consequences is in the same boat if she almost never encounters circumstances in which a non-libertarian judgment is appropriate. This failure is evidence that her view of the facts is at least partially confabulatory. In effect, it is evidence that (a) her libertarianism trumps her consequentialism and (b) that libertarianism drives her perception of the facts, allowing her to maintain the façade of consequentialism. Of course, exactly the same would be true of someone who justified her characteristically deontological, or virtue theoretical (and so on) judgments on her perception of the facts, if she, too, very rarely encountered circumstances that justified divergent assessments.

We may be tempted, to think that someone who adopts a purer form of consequentialism is in the clear. Here's why: plausibly, Greco's consequentialist-libertarian and others who adopt parallel views are vulnerable to confabulation in virtue of their attachment to libertarianism (virtue ethics, rights, or what have you). This commitment acts as a biasing influence, driving their perception of the consequences. But those who adopt more purely consequentialist views are free of this distorting influence. An implicit or explicit commitment to a nonconsequentialist value does not distort their perception of the implicated facts.

But purer consequentialists are not automatically off the hook. Unless the world is much more conveniently arranged than we have any reason to believe, we ought to expect consequentialists to sometimes - perhaps often - encounter situations in which they make judgments that entail significant costs, measured in dispute-independent goods. That is, they should be readier than they seem to be to accept that sometimes the right action, from their point of view, is right in spite of significant ill-effects (significant though of course outweighed by the benefits). Take, for example, the standard response to the over-demandingness objection: insistence that in the real world, an agent who sacrificed too much on the altar of morality would soon burn out and would therefore fail to bring about the best consequences. Perhaps so, but it looks mighty convenient.

Indeed, there is room for suspicion in the fact that consequentialists seem too rarely to take themselves to encounter circumstances in which they must pay costs measured in disputed goods. A standard response to counterexamples to consequentialism turning on rights violations (Thomson's (1985) surgeon case, punishment of the innocent, and so on) is, after all, to argue that in the real world these rights-violating actions would not maximize welfare, preference satisfaction, or what have you. The acts could not be kept secret and therefore anxiety levels would rise throughout society; engaging in actions like this would corrupt the agent's character, leading her to act in ways that don't bring about good consequences, and so on (see, for a recent example, de Lazari-Radek and Singer 2014). Again, the response is suspiciously convenient.

To escape suspicion, consequentialists must not only bite the bullet on (say) rights violations - demonstrating a real willingness to countenance costs measured in goods they do not accept - but also on dispute-independent goods. Cases in which the right thing to do the course of action that brings about the best consequences - entails significant costs measured in goods consequentialists themselves value should not be vanishingly rare. If dispute-independent costs are very rarely significant, as the consequentialist see things, we have grounds for suspicion with regard to their assessments of the facts. Again, the actual responses of consequentialists often seem to me suspicious. I suspect that what often happens is that while consequentialists (genuinely) form an initial judgment on a basis of a clear-eyed 
assessment of the consequences of various courses of action, their subsequent assessment of further facts, facts they had not considered in forming their initial judgment, tends to be influenced by this judgment illicitly. Recall, here, the pro-enhancement views of some consequentialists. They foresee suspiciously few negative externalities of enhancement.

Neither the consequentialist nor Greco's consequentialist-libertarian is automatically in the clear, then, despite the fact that we ought to expect a good match between their judgments and the implicated facts. Consequentialists, too, may - and often do - evince the pattern of correlations that indicate that they live in a suspiciously benign world. ${ }^{5}$ Unless we live in a world that is morally benign, we ought to expect to pay some costs for doing the right thing, and suspicion should be aroused by those who almost never see themselves as needing to pay them. No one is off the hook, then, merely in virtue of their theoretical commitments.

Another strategy for resisting the pressure to conciliate may focus on the inference from the pattern of judgments I evince is suspicious to I should reduce my confidence in this token belief. Inferences from global patterns are indeed sometimes perilous. For instance, some patterns that emerge at the global level are the product of influences that at the individual level are swamped by other factors. It is often claimed, for example, that there are more differences within ethnic groups than between them (Heyer et al. 2009), and when data is noisy, average differences between groups may not be good guides to the properties of the individual members (for example, the average age of a group might be 30 , but most members of the group very much older or younger than the average). The suspicious correlation seems, however, to involve an influence that is strong enough to worry us in individual cases. It does not take sophisticated statistical analysis of a large number of cases to detect it. It seems to me to be detectable at the individual level (in myself).

A final way to resist the pressure to conciliate is to hold that any such pressure is already entirely captured by peer disagreement. The cases in which suspicious correlations are most easily seen are, after all, cases in which our moral judgments, and our assessments of the implicated facts, are controversial. One may worry that the problem of suspicious correlations is reducible to the problem of peer disagreement, or, more weakly, that it does not give us any additional reason to conciliate with regard to any particular belief. Neither worry is well-founded.

One way to see that the significance of peer disagreement is distinct from that of the suspicious correlation is to examine the beliefs thrown into doubt by them. Peer disagreement gives us equal reason to conciliate about each belief that is contested. If Karina and Wei are epistemic peers who disagree about abortion and about the implicated facts, recognition of their disagreement gives them prima facie reason to conciliate on both moral judgment and the facts. ${ }^{6}$ But if they have reason to think that the correlation between their moral judgments

\footnotetext{
${ }^{5}$ This is no more than a friendly amendment to Greco's view. He recognizes that a pattern of matches between stances based on consequences may be suspicious - he cites the Team Player, who supports every policy his party espouses, ostensibly on the grounds that these policies are each best designed to secure dispute-independent goods.

${ }^{6}$ Of course, there are various strategies for resisting the pressure to conciliate, some available to conciliationists and some only to those who reject conciliationism. Even conciliationists maintain that we may often hold fast because we have few epistemic peers, or because setting aside the dispute and all the reasons implicated in it, we have no basis for thinking that dissenters would be as likely as we are to come to the right response (Elga 2007; see Fritz 2018; McGrath 2008 for discussion), while level splitting views maintain that we can hold fast on the basis of first-order evidence alone (Horowitz 2014). The suspicious correlation seems immune to worries that arise from peerhood, since it arises independently of actual disagreement, as we'll see. Whether level splitting views might be adapted to resist the pressure to conciliate I leave to those who find these views palatable in any case.
} 
and the implicated facts is suspicious, they have reason to conciliate on the latter alone, since the correlation appears to arise as a consequence of the biasing influence of the former on the latter. The fact that the suspicious correlation and peer disagreement do not overlap in the beliefs they identify for concern is good evidence that they are distinct problems. But if they are distinct, then the pressure that arises from suspicious correlations is additional to any pressure to conciliate that arises from peer disagreement. Since the latter belief is correlated with the former, it inherits from it the suspicion that attaches to the former. But since it is also biased by that belief, it is subject to additional pressure. Any reason we had to clear the moral judgment of suspicion arising from peer disagreement would not entirely clear the assessment of the implicated facts: that assessment might still be biased.

Another way to see that the problems are distinct is to notice how disagreement and the suspicious correlation interact. While disagreement cases in which agents disagree over both moral judgments and implicated facts, like the disagreement between Wei and Karina, are very common, there are of course cases in which $A$ and $B$ share their moral judgments but diverge in their assessments, and cases in which they diverge in their moral judgments but converge in their assessments. In the first kind of case, one of the agents holds that the morally best course of action entails dispute-independent costs, whereas the other denies this. This dispute provides the agent with the rosier view of the consequences with an extra reason to reduce her confidence. Recall that the suspicious correlation likely arises from some kind of biasing effect of moral judgment on factual perception, such that we are disposed to see the non-moral facts as fitting suspiciously well with our evaluations. An agent who shares my moral judgment but sees it as entailing costs (measured in dispute-independent goods) appears to be less subject to that bias. Thus, my moral fellow traveller puts extra pressure on me to conciliate on the non-moral facts.

What about the agent who shares my view of the implicated facts but diverges in her moral judgment? While we can imagine cases in which divergent moral judgments drive similar, but equally confabulated, perceptions of the implicated facts (perhaps due to differences in attitudes toward those facts), in general, this cross-party disagreement is evidence that at least one of us is not subject to distortion due to a biasing factor, and therefore in favour of our shared assessment. By indicating that one of us (at least) has resisted the pressure to bias her assessment of the implicated facts, it provides evidence that the facts really are as we both take them to be. We might compare agents in this kind of situation to those who know that one or the other (but not both) is under the influence of a drug that distorts perceptions of reality in some of those who take it (perhaps they know the drug is dissolved in one or other of the glasses from which they have drunk). If the two agents disagree about some fact, they have reason to conciliate: they know that one of them might be distorted in their perception, but they have no more reason to think it is the other agent than themselves. But if they agree they have evidence that neither has had their perception of the fact on which they agree distorted by the drug and they can disregard its influence. Analogously, two agents who disagree in their moral judgments but not about their perceptions of implicated facts can set aside worries about the biasing influences of the former on the latter.

The evidence provided by agreement about implicated facts in these kinds of cases is stronger still when the implicated facts are recognized to be costs that one agent must pay in virtue of her judgment. The fact that she sees these facts as entailing costs is evidence that her perception is not motivated (of course, we can imagine perverse cases, in which agents are motivated to see things as worse than they really are, but cases like this are far outnumbered by 
those in which the bias goes the other way; Gilovich 1993). ${ }^{7}$ Importantly, these implications arise from the interaction of the suspicious correlation and disagreement cases. Setting aside the former, the fact that I disagree with Tomas about $x$ but not $y$ tells me nothing about what my attitude to $x$ should be that I did not know already in light of the fact that Tomas is my epistemic peer. If the suspicious correlation can interact with the problem of disagreement in this way, the problems must be distinct.

While it is true that the suspicious correlation is most easily seen in peer disagreement cases, it is a mistake to think that the pressure to conciliate (or, at any rate, to lower our confidence in our assessments) it gives rise to requires peer disagreement. We can be confident that people in general, and (I strongly suspect) ourselves, are apt to manifest the suspicious correlation by noting that when we disagree with epistemic peers about moral issues, we also tend to hold contrasting, but equally rosy, beliefs about the implicated facts. Once we possess this knowledge about our dispositions, we no longer need to identify a dissenting peer to worry that a token assessment of implicated facts is biased by the mechanisms we have identified here. Worries about the suspicious correlation are thus independent of worries about peer disagreement.

\section{Conclusion}

The extent to which each of us takes the world to support our moral judgments is suspicious. We are apt to take the facts to cooperate with our judgments, even when we have not formed those judgments by reference to the implicated facts. We even expect the facts to change obligingly if we happen to change our moral judgments. These facts suggest that our assessment of the implicated facts is biased, and that, in turn, gives us reason to reduce our confidence in this assessment. Just as recognition of disagreement with an epistemic peer gives us reason to conciliate, so recognition that we are subject to a pattern of suspicious correlations gives us reason to conciliate.

The pressure arising from the suspicious correlation is lower than that arising from disagreement. The most discussed, and perhaps the most widely held, position on the epistemic significance of disagreement is the equal weight view (Elga 2007; Christensen 2007; Matheson 2015). According to the equal weight view, in peer disagreement cases your reasons for thinking you are mistaken are as strong as your reasons for holding firm. ${ }^{8}$ The

\footnotetext{
${ }^{7}$ The claim that recognition that another agent takes her judgment to entail costs is evidence that she is less biased is intended as a normative claim, but it is worth noting that there is evidence that ordinary agents assess testimony that is contrary to testifiers' ideological interests as more credible than testimony that is consistent with such interests (Berinsky 2017).

${ }^{8}$ The equal weight view might motivate an objection to the claim that the suspicious correlation offers us an independent reason to reduce our confidence in some of our beliefs. Suppose you and I are epistemic peers, and we disagree about moral judgment $j$ and implicated facts $f$. If the equal weight view is correct, my confidence in my initial assessment with regard to $f$ should be 0.5 . If the suspicious correlation is correct, and I should conciliate even further, I would have to reduce my confidence below 0.5 . But that would allow me to bootstrap my way to a degree of confidence in a way that just cannot be right, especially given that my position is symmetrical to yours, and you are required to move in the opposite direction. Perhaps the strong grounds for thinking that the suspicious correlation is independent of the argument from peer disagreement gives us reasons to reject the equal weight view, in favour of a weaker conciliationism, in order to avoid this absurd result. I prefer a different response: distinguishing between how strong our reasons in favour of conciliation are and how much we are required to conciliate. In those cases in which the equal weight response is most plausible, any suspicious correlation does not give us reason to conciliate even more, but it does give us even stronger reason to conciliate.
} 
suspicious correlation does not offer anything so strong. While I should be suspicious regarding the pattern of correlation across my beliefs, taken by itself (that is, in isolation) the correlation is not a reason to lower my confidence in my assessments to 0.5 . While I should be confident that my bias has painted too rosy a picture of the implicated facts, the extent to which my perception is skewed is an open question. The suspicious correlation may be better construed as an argument in favour of epistemic humility with regard to our assessment of the implicated facts, rather than as generating advice to conciliate to some specific extent. ${ }^{9}$

Acknowledgements I am grateful to audiences at the Australasian Association of Philosophy Conference in Wollongong and at Tilburg University for helpful feedback on this paper.

Funding Information Supported by a grant from the Australian Research Council (DP180102384).

Data Availability N/A

\section{Compliance with Ethical Standards}

\section{Conflict of Interest N/A}

\section{Code Availability N/A}

Open Access This article is licensed under a Creative Commons Attribution 4.0 International License, which permits use, sharing, adaptation, distribution and reproduction in any medium or format, as long as you give appropriate credit to the original author(s) and the source, provide a link to the Creative Commons licence, and indicate if changes were made. The images or other third party material in this article are included in the article's Creative Commons licence, unless indicated otherwise in a credit line to the material. If material is not included in the article's Creative Commons licence and your intended use is not permitted by statutory regulation or exceeds the permitted use, you will need to obtain permission directly from the copyright holder. To view a copy of this licence, visit http://creativecommons.org/licenses/by/4.0/.

\section{References}

Baron J, Jost JT (2019) False equivalence: are liberals and conservatives in the US equally "biased?'. Perspect Psychol Sci 4:292-303

Berinsky AJ (2017) Rumors and health care reform: experiments in political misinformation. Br J Polit Sci 47: 241-262. https://doi.org/10.1017/S0007123415000186

Birch K (2005) Beneficence, determinism and justice: an engagement with the argument for the genetic selection of intelligence. Bioethics 19:12-28

Cakic V (2009) Smart drugs for cognitive enhancement: ethical and pragmatic considerations in the era of cosmetic neurology. J Med Ethics 35:611-615

Chatterjee A (2004) The controversy over enhancing movement, mentation, and mood. Neurology 63:968-974

Christensen D (2007) Epistemology of disagreement: the good news. Philos Rev 116:187-217. https://oi. org/10.1215/00318108-2006-035

Christensen D, Lackey J (2013) The epistemology of disagreement: new essays. Oxford University Press

Clarke S (2017) A Prospect Theory Approach to Understanding Conservatism. https://philpapers. org/rec/CLAAPT-9. Accessed 10 Mar 2019

\footnotetext{
${ }^{9}$ I am grateful to two reviewers for this journal, as well as an audience at Tilburg University for very helpful comments. Work leading to the publication of this paper was supported by a generous grant from the Australian Research Council (DP180102384).
} 
de Lazari-Radek K, Singer P (2014) The point of view of the universe: Sidgwick and contemporary ethics. Oxford University Press, Oxford

Ditto PH, Liu BS, Clark CJ et al (2018) At least bias is bipartisan: a meta-analytic comparison of partisan bias in liberals and conservatives. Perspect Psychol Sci 1745691617746796

Elga A (2007) Reflection and disagreement. Noûs 41:478-502

Franklin J (2009) Evidence gained from torture: wishful thinking, checkability, and extreme circumstances. Cardozo J Int Comp Law 17:281-290

Fritz J (2018) Conciliationism and moral spinelessness. Episteme 15:101-118. https://doi.org/10.1017 /epi.2016.44

Fukuyama F (2002) Our Posthuman future. Farrar, Straus and Giroux

Gilovich T (1993) How we know what Isn't so: the fallibility of human reason in everyday life, Reprint edn. Free Press, New York Great Britain

Greco D (n.d.) Climate change and cultural cognition. In: philosophy and climate change. Oxford University Press

Habermas J (2003) Future of human nature. Polity Press, Cambridge

Hauskeller M (2013) Better Humans?, 1 edition. Routledge, Durham, Bristol

Heyer E, Balaresque P, Jobling MA, Quintana-Murci L, Chaix R, Segurel L, Aldashev A, Hegay T (2009) Genetic diversity and the emergence of ethnic groups in Central Asia. BMC Genet 10:49. https://doi. org/10.1186/1471-2156-10-49

Horowitz S (2014) Epistemic Akrasia. Nous 48:718-744

Joshi $\mathrm{H}$ (2020) What are the chances you're right about everything? An epistemic challenge for modern partisanship - Hrishikesh Joshi. Polit Philos Econ 19:36-61

Kahan DM, Braman D, Slovic P et al (2007) The second National Risk and culture study: making sense of - and making Progress in - the American culture war of fact. Social Science Research Network, Rochester

Kahan DM, Jenkins-Smith H, Braman D (2010) Cultural cognition of scientific consensus. Social Science Research Network, Rochester

Kahan DM, Jenkins-Smith H, Tarantola T, Silva CL, Braman D (2015) Geoengineering and climate change polarization: testing a Two-Channel model of science communication. Ann Am Acad Pol Soc Sci 658:192222. https://doi.org/10.1177/0002716214559002

Lambert EG, Clarke A, Lambert J (2004) Reasons for supporting and opposing capital punishment in the USA. Internet J Criminol 1:1-34

Liu BS, Ditto PH (2013) What dilemma? Moral evaluation shapes factual belief. Soc Psychol Personal Sci 4: 316-323. https://doi.org/10.1177/1948550612456045

Lord CG, Ross L, Lepper MR (1979) Biased assimilation and attitude polarization: the effects of prior theories on subsequently considered evidence. J Pers Soc Psychol 37:2098-2109. https://doi.org/10.1037/00223514.37.11

Matheson J (2015) The epistemic significance of disagreement. Palgrave Macmillan

McGrath S (2008) Moral disagreement and moral expertise. In: Shafer-Landau R (ed) Oxford studies in Metaethics. Oxford University Press, New York, pp 87-108

Owens D (1992) Causes and coincidences. Cambridge University Press, Cambridge, New York

Sandberg A, Savulescu J (2014) The social and economic impacts of cognitive enhancement. In: Enhancing human capacities. John Wiley \& Sons, Ltd, pp 92-112

Sandel MJ (2009) Case against perfection. Harvard University Press, Cambridge, London

Seipel P (2019) Why do we disagree about our obligations to the poor? Ethical Theory Moral Pract 22:121-136

Stack S (2004) Public opinion on the death penalty. Int Crim Justice Rev 14:69-98. https://doi.org/10.1177 $/ 105756770401400104$

Thomson JJ (1985) The trolley problem. Yale Law J 94:1395. https://doi.org/10.2307/796133

van der Linden SL, Leiserowitz AA, Feinberg GD, Maibach EW (2015) The scientific consensus on climate change as a gateway belief: experimental evidence. PLoS One 10:e0118489. https://doi.org/10.1371/journal. pone. 0118489

van der Linden SL, Leiserowitz A, Maibach E (2019) The gateway belief model: a large-scale replication. J Environ Psychol 62:49-58. https://doi.org/10.1016/j.jenvp.2019.01.009

Veit W (2018) Cognitive enhancement and the threat of inequality. J Cogn Enhanc 2:1-7

Wolbring G (2009) What next for the human species? Human performance enhancement, ableism and pluralism. Dev Dialogue 52:141-163

Publisher's Note Springer Nature remains neutral with regard to jurisdictional claims in published maps and institutional affiliations. 